\title{
Potensi Ekowisata Hutan Mangrove Klawalu Kota Sorong Papua Barat
}

\author{
Lusye Naa'; Charly B Wanggai'; Rima H S Siburian ${ }^{3}$ \\ Fakultas Kehutanan Universitas Papua \\ [3.siburian@uipa.ac.id
}

\begin{abstract}
Abstrak
Klawalu merupakan salah satu daerah di Kota Sorong yang memiliki potensi mangrove yang masih terjaga secara alami. Sejalan dengan pengembangan pembangunan maka ekowisata merupakan alternatif yang perlu dipertimbangkan dalam menjaga ekosistim kawasan dengan tetap meningkatkan ekonomi masyarakat sekitar. Tujuan penelitian ini adalah untuk mengetahui potensi ekowisata hutan mangrove Klawalu Kota Sorong. Metode yang digunakan adalah metode deskritif dengan teknik observasi lapangan dan wawancara berpedoman pada analisis ADO-ODTWA Dirjen PHKA Tahun 2003. Hasil penelitian menunjukkan bahwa nilai kriteria obyek dan daya tarik kawasan memiliki nilai tertinggi dengan total skor 960. Hal ini menunjukkan bahwa kawasan ekowisata mangrove Klawalu memiliki tingkat keunikan yang didukung oleh flora dan fauna penyusunannya dengan aksesisibilitas serta sarana dan prasarana penunjang serta ketersediaan air bersih yang dapat digunakan sebagai daerah pengembangan ekowisata yang sangat baik. Dari unsurur penilaian yang dilakukan baik terhadap aksesibilitas, kondisi lingkungan sekitar kawasan, maupun ketersediaan air bersih menunjukkan bahwa kawasan ini siap untuk menjadi destinasi wisata yang dapat dikembangkan.
\end{abstract}

Kata kunci: Potensi ekowisata, obyek dan daya tarik, Hutan mangrove, Klawalu

\section{PENDAHULUAN}

Papua merupakan salah satu wilayah di Indonesia yang memiliki kawasan hutan mangrove yang luas, meskipun deforestasi dan degradasi kawasan terus terjadi (Jerisetouw 2005, Mundoni D, 2019). Berbagai kebijakan dalam mendorong pola pemanfaatan sumberdaya pesisir dan laut secara berkelanjutan terus dilakukan, salah satu diantaranya adalah peningkatan nilai ekonomi kawasan dengan tetap mempertahankan konsep ekologi melalui pengembangan kawasan ekowisata.

Sejalan dengan pergeseran minat wisatawan terhadap nilai pendidikan dan konservasi, maka kawasan ekowisata merupakan alternatif yang sangat baik dalam mempertahankan dan meningkatkan nilai suatu kawasan. Berbagai upaya dalam pengelolaan dan pengembangan kawasan wisata yang spesifik dan unik perlu dikembangkan dengan tetap mempertahankan kondisi ekologi kawasan serta keanekaragaman jenis penyusunnya.

Ekowisata merupakan salah satu produk pariwisata alternatif yang mempunyai tujuan membangun pariwisata berkelanjutan yaitu pembangunan pariwisata yang secara ekologis memberikan manfaat yang layak secara ekonomi dan adil secara etika, serta memberikan manfaat sosial terhadap masyarakat. Ekowisata saat ini menjadi salah satu 


\section{Median Volume 12 Nomor 2 Bulan 2020}

Doi http://doi.org/md.v12i2.631

pilihan dalam mempromosikan lingkungan yang khas terjaga keaslihan sekaligus menjadi suatu kawasan kunjungan wisata. Potensi ekowisata adalah konsep pengembangan lingkungan yang berbasis pada pendekatan pemeliharaan dan konservasi alam. Salah satu bentuk ekowisata yang dapat melestarikan lingkungan yakni dengan ekowisata mangrove.(Pratama,2017)

Kawasan hutan mangrove Ekowisata Mangrove Klawalu merupakan salah satu kawasan mangrove yang berada di Kota Sorong Papua Barat. Kawasan ini memiliki potensi yang besar untuk dikembangkan sebagai salah satu daerah wisata. Potensi dan daya tarik wisata apa yang dapat dikembangkan didaerah ini, serta berapa nilai keindahan potensi serta daya tarik yang diberikan oleh pengunjung terhadap obyek wisata disekitar kawasan hutan mangrove ini, perlu dilakukan penelitian lebih lanjut, guna memaksimalkan nilai ekonomi dan ekologis kawasan. Untuk itu tujuan penelitian ini adalah untuk mengetahui potensi ekowisata hutan mangrove Klawalu Kota Sorong.

\section{METODE PENELITIAN}

Penelitian ini dilakukan di Kelurahan Klawalu Distrik Sorong Timur, dengan luas wilayah $19.16 \mathrm{~km} 2$. Objek dalam penelitian ini adalah potensi ekowisata yang terdapat di kelurahan Klawalu Kota Sorong Papua Barat. Adapun alat yang digunakan diataranya kamera, alat tulis menulis serta buku pedoman lapangan.

Data yang dikumpulkan dalam penelitian meliputi data primer seperti jenis-jenis mangrove dan fauna yang dijumpai dalam kawasan, obyek dan daya tarik alam, jenis kegiatan wisata yang telah ada. Serta persepsi dan harapan pengunjung yang merupakan responden dalam penelitian ini.

Metode yang di gunakan dalam penelitian ini adalah metode deskritif dengan teknik observasi lapangan dan wawancara dengan mengunakan pedoman analisis ADOODTWA Dirjen PHKA Tahun 2003 yang telah dimodifikasi. Variabel yang di amati dalam penelitian ini adalah :

1. Objek dan daya tarik Kawasan Wisata Hutan Mangrove Klawalu

2. Kondisi aksibilitas, dan fasilitas pendukung sarana prasarana pada Kawasan Wisata Hutan Mangrove Klawalu

Setelah itu data yang dikumpulkan dinilai berdasarkan unsur dan sub unsur yang saling berkaitan dengan kondisi pada kawasan Wisata Hutan Mangrove Klawalu. Daya tarik dan ketersediaan air bersih merupakan faktor terbesar yang mempengaruhi seseorang mengunjungi suatu kawasan sehingga bobot yang diberikan sebesar 6 . Sedangkan untuk penilaian aksesibilitas dan kondisi lingkungan diberi skor 5. Untuk fasilitas sarana prasarana penunjang diberi skor 3. Hasil penilaian ini digunakan untuk memberikan masukan bagi pengembangan obyek wisata pada kawasan ini. 


\section{Median Volume 12 Nomor 2 Bulan 2020}

Doi http://doi.org/md.v12i2.631

\section{HASIL DAN PEMBAHASAN}

\section{Daya Tarik Kawasan Hutan Mangrove Klawalu}

Atraksi wisata merupakan salah satu sumber daya tarik bagi wisatawan untuk mengunjungi suatu lokasi. Alaeddinoglu et al (2013) menyatakan bahwa daya tarik suatu tempat wisata merupakan nilai penting dalam motifasi pengunjung untuk melakukan kunjungan wisata. Dalam pengembangannya aspek ekologis tetap harus dapat dipertahankan disamping nilai ekonomi yang diharapkan. Mangrove merupakan salah satu kawasan hutan yang memiliki nilai pendidikan, ekologis serta ekonomi yang dapat dikembangkan sebagai kawasan ekowisata.

Kawasan Hutan Mangrove Klawalu merupakan salah satu kawasan yang memiliki sumberdaya mangrove yang sangat menarik di kota Sorong. Sehubungan dengan perkembangan kota dan kebutuhan masyarakat akan tempat wisata maka pada akhir tahun 2018, kawasan ini dirintis sebagai daerah ekowisata yang dikelola oleh pemerintah daerah Kota Sorong. Adapun wilayah yang dikelola seluas $1 \mathrm{Ha}$, seperti pada Gambar 1.

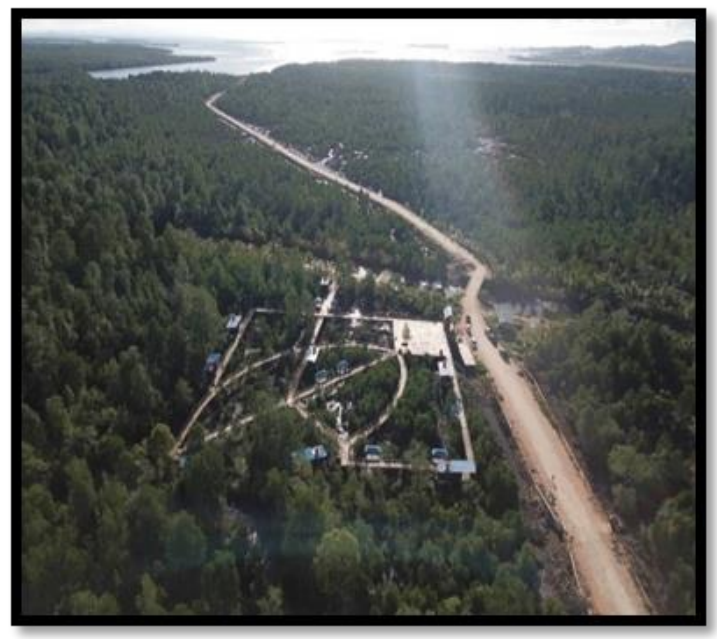

(a)

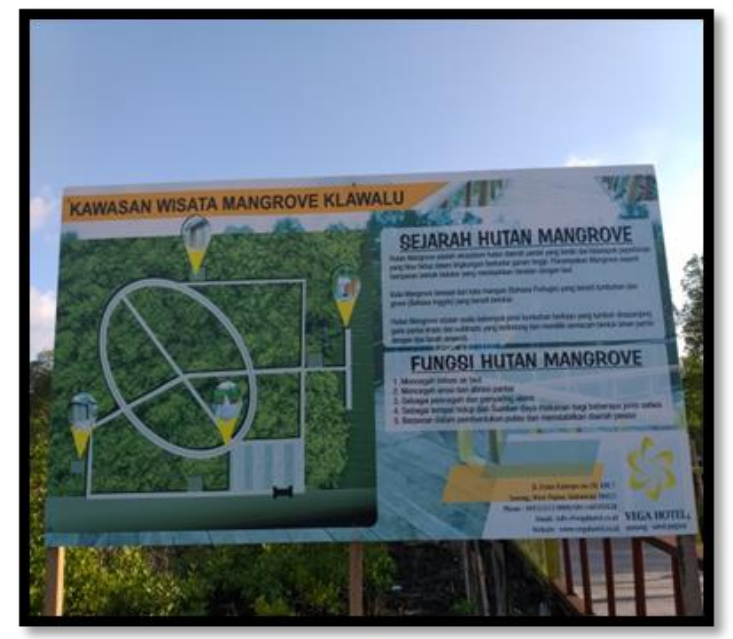

(b)

Gambar 1 (a) Kawasan Wisata Hutan Mangrove Klawalu, (b) Spanduk Kawasan Hutan Mangrove

Pengukuran daya tarik yang dilakukan terhadap kawasan wisata hutan mangrove Klawalu ini adalah : Keindahan sumberdaya alam, keunikan sumberdaya alam, banyaknya sumberdaya alam, keutuhan dan kepekaan sumberdaya alam, jenis kegiatan wisata alam yang dapat dilakukan, serta kebersihan dan keamanan kawasan seperti disajikan dalam Tabel 1. 


\section{Median Volume 12 Nomor 2 Bulan 2020}

Doi http://doi.org/md.v12i2.631

Tabel 1 Penilaian Kriteria obyek dan daya tarik kawasan Ekowisata Mangrove Klawalu

\begin{tabular}{clccc}
\hline No. & \multicolumn{1}{c}{ Kiteria dan Unsur Penilaian } & Bobot & Nilai & $\begin{array}{c}\text { Skor } \\
\text { Total }\end{array}$ \\
\hline 1. & Keindahan Alam & 6 & 25 & 150 \\
2. & Keunikan Sumberdaya alam & 6 & 20 & 120 \\
3 & Banyaknya Sumberdaya alam yang menonjol & 6 & 20 & 120 \\
4. & Keutuhan Sumberdaya alam & 6 & 25 & 150 \\
5. & Kepekaan Sumberdaya alam & 6 & 20 & 120 \\
6. & Jenis kegiatan wisata alam & 6 & 20 & 120 \\
7. & Kebersihan lokasi & 6 & 30 & 180 \\
\hline & Jumlah Skor Total & & $\mathbf{1 6 0}$ & $\mathbf{9 6 0}$ \\
\hline
\end{tabular}

Sumber: Data Primer 2019

Berdasarkan hasil pengamatan Kawasan wisata Hutan Mangrove Klawalu memiliki nilai keindahan dengan perpaduan sarana prasarana penunjang yang telah dibuat oleh pengelola kawasan sehingga lokasi ini memiliki nilai keutuhan keindahan yang sangat menarik. Adapun beberapa jenis mangrove yang dapat dijumpai pada kawasan ini diantaranya Rhizophora stylosa, Bruguiera gymnorrhiza, Xylocarpus granatum, Sonneratia caseolaris, Avicennia alba, Rhizophora apiculata, Bruguirea parviflora dan Ceriops tagal. Jenis fauna yang dijumpai pada daerah ini diantaranya Common mine, Scylla sp, Uca spp, Metaplax sp, Metapograpsus sp, Alpheus sp, Nerita $s p$, Periopthalmus sp, Alpheus spp, Coenobita sp, Clibanarius sp serta beberapa jenis burung yang menambah keindahan daerah ini, seperti dapat dilihat pada Gambar 2.

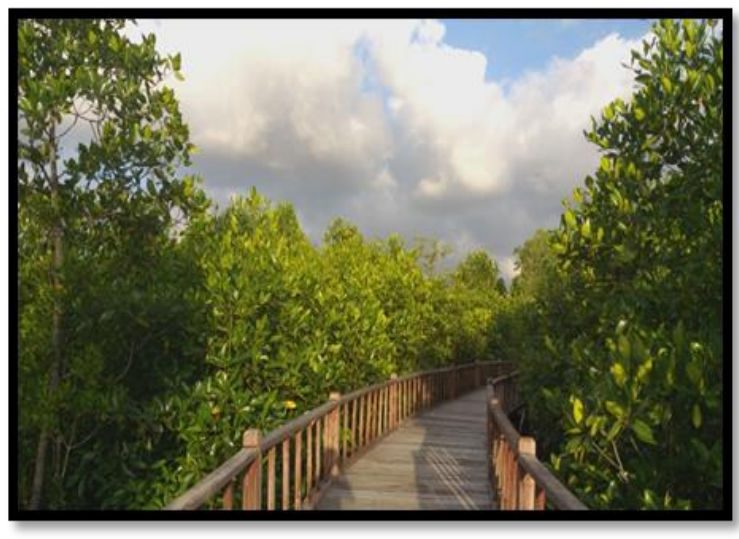

(a)

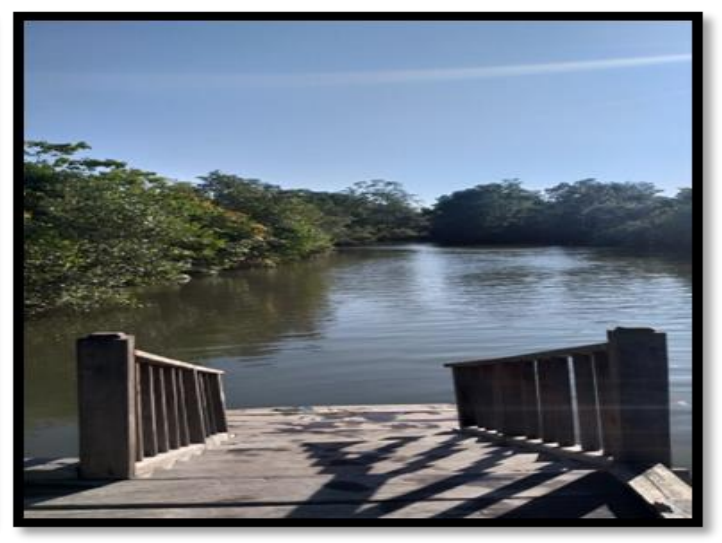

(b)

Gambar 2. (a) Keunikan Vegetasi Mangrove, (b) Sungai Klawalu

Keutuhan sumberdaya alam yang ada pada lokasi meliputi kondisi geologi, flora dan fauna serta keadaan lingkungan alam sekitar sangat menunjang kelestarian kondisi alam. Rusita 2017 menyatakan bahwa kesatuan unsur-unsur fisik dan biologi merupakan faktor penentu keutuhan dalam mendukung daya tarik suatu objek wisata. Hasil penilaian keutuhan dan kepekaan sumberdaya alam menujukan bahwa keterpaduan antara unsur-unsur flora, dan kulialitas/kondisi lingkungan di Sekitar Kawasan Wisata Hutan Mangrove Klawalu sangat mendukung keberlajutan pengelolaan 


\section{Median Volume 12 Nomor 2 Bulan 2020}

Doi http://doi.org/md.v12i2.631

kawasan ini sebagai daerah ekowisata. Vegetasi yang terdapat pada kawasan menjadi salah satu daya tarik wisata, disamping fauna endemik yang ada. Keaslian panorama alam yang dipadukan dengan penyusun ekosistem dan hidrologis sebagai daya tarik tersendiri gabi kawasan ini.

\section{Aksesibilitas}

Aksesibilitas merupakan salah satu faktor penting yang membantu wisatawan dalam mengunjungi kawasan wisata. Pada kawasan ini, tingkat aksesibilitas yang dinilai meliputi kondisi jalan, jarak tempuh, tipe jalan dan waktu tempuh dari pusat kota serta frekuensi kendaraan yang digunakan. Dengan demikian maka tingkat aksesibilitas kawasan ini tergolong baik karena dapat ditempuh dengan menggunakan kendaraan baik roda dua maupun empat, dengan jarak tempuh $10 \mathrm{~km}$ dalam waktu \pm 40 menit. Disamping itu kendaraan umum yang menuju lokasi juga tersedia, sekalipun jalan masuk menuju lokasi belum diaspal. Hal ini menunjukkan bahwa akses pengunjung ke lokasi sangat mudah. Ginting et al (2013) yang menyatakan bahwa salah satu faktor yang membuat suatu kawasan menarik adalah tingkat aksesibilitasnya seperti letak lokasi dengan bandar udara internasional; pusat kota ataupun tingkat kemudahan dalam mencapai lokasi. Aksesibilitas berdasarkan hasil penilaian pada kawasan seperti disajikan dalam Tabel 2.

Tabel 2 Penilaian Kriteria aksesibilitas menuju kawasan Ekowisata Mangrove Klawalu

\begin{tabular}{llccc}
\hline \multicolumn{1}{c}{ Ko. Kiteria dan Unsur Penilaian } & Bobot & Nilai & $\begin{array}{c}\text { Skor } \\
\text { Total }\end{array}$ \\
\hline 1. & Kondisi dan jarak jalan darat & & & \\
& $\leq 5 \mathrm{Km}$ & 5 & 40 & 200 \\
& $>5-10 \mathrm{Km}$ & 5 & 40 & 200 \\
& $>10-15 \mathrm{Km}$ & 5 & 30 & 150 \\
$\quad>15 \mathrm{Km}$ & 5 & 20 & 100 \\
2. Tipe Jalan & 5 & 30 & 150 \\
3. & Kebersihan lokasi & 5 & 30 & 150 \\
\hline & Jumlah Skor Total & & $\mathbf{1 8 0}$ & $\mathbf{9 5 0}$ \\
\hline
\end{tabular}

Sumber: Data Primer 2019

\section{Kondisi Lingkungan Sekitar Kawasan}

Ketersedian lahan pengembangan merupakan potensi areal yang dapat dipergunakan sebagai areal wisata. Tata ruang wilayah objek kawasan wisata hutan mangrove ini telah sesuai dengan pengembangan wilayah daerah. Umumnya mata pencaharian penduduk yang hidup disekitar kawasan adalah sebagai nalayan, petani, pedagang dan pengrajin, dengan pendidikan akhir masyarakat umumnya adalah tamat SMA. Adapun hasil penilaian terhadap kriteria kondisi lingkungan disekitar kawasan mangrove seperti pada Tabel 3. 


\section{Median Volume 12 Nomor 2 Bulan 2020}

Doi http://doi.org/md.v12i2.631

Tabel 3 Penilaian Kriteria Kondisi Lingkungan disekitar kawasan Ekowisata Mangrove Klawalu

\begin{tabular}{clccc}
\hline No. & \multicolumn{1}{c}{ Kiteria dan Unsur Penilaian } & Bobot & Nilai & $\begin{array}{c}\text { Skor } \\
\text { Total }\end{array}$ \\
\hline 1. & Tata ruang wilayah Kawasan hutan mangrove & 5 & 30 & 150 \\
2. & Mata Pencaharian penduduk & 5 & 25 & 125 \\
3 & Ruang gerak pengunjung & 5 & 25 & 125 \\
4. & Pendidikan & 5 & 25 & 125 \\
5. & Persepsi mayarakat terhadap pengembangan kawasan & 5 & 30 & 150 \\
\hline & Jumlah Skor Total & & $\mathbf{1 3 5}$ & $\mathbf{6 7 5}$ \\
\hline
\end{tabular}

Sumber: Data Primer 2019

\section{Sarana Prasarana}

Sarana yang tersedia dalam Kawasan Wisata Hutan Mangrove Klawalu adalah akomodasi berupa tempat-tempat duduk untuk menikmati keindahan alam, spot-spot foto menarik, menara pandang, areal parker, fasilitas untuk jalan menikmati kawasan diatas mangrove dan juga kamar mandi. Sedangkan sarana prasarana yang tersedia dalam radius $10 \mathrm{~km}$ untuk menunjang pengelolaan kawasan obyek ekowisata meliputi dermaga, jaringan komunikasi, Puskesmas jaringan listrik. Disamping itu ada juga pasar, bank, took souvenir serta angkutan umum. Hasil penilaian terhadap kriteria pendukung berupa sarana prasarana pada kawasan seperti di sajikan dalam Tabel 4.

Tabel 4. Penilaian Kriteria sarana Prasarana dalam kawasan Ekowisata Mangrove Klawalu

\begin{tabular}{clccc}
\hline No. & Kiteria dan Unsur Penilaian & Bobot & Nilai & $\begin{array}{c}\text { Skor } \\
\text { Total }\end{array}$ \\
\hline 1. & Sarana & 3 & 30 & 90 \\
2. & Prasarana & 3 & 30 & 90 \\
\hline & Jumlah Skor Total & & $\mathbf{6 0}$ & $\mathbf{1 8 0}$ \\
\hline
\end{tabular}

Sumber: Data Primer 2019

\section{Ketersedian Air Bersih}

Sumber air bersih yang digunakan dalam Kawasan Wisata Hutan Mangrove Klawalu berasal dari pengelolaan air Sungai Klawalu. Volume air sungai klawalu tergolong cukup untuk pemenuhan kebutuhan masyarakat disekitar kawasan. Jarak sumber air dari lokasi kawasan wisata sangat dekat dan mudah untuk dialirkan, bahkan debit air sungai Klawalu tersedia sepanjang tahun. Bila dilihat kondisi sungai klawalu untuk langsung dikonsumsi sebagai air minum, kurang layak karena warnanya yang kurang jernih, perlu dilakukan pengolahan terlebih dahulu. Adapun hasil penilaian ketersediaan air bersih seperti disajikan dalam Tabel 5. 


\section{Median Volume 12 Nomor 2 Bulan 2020}

Doi http://doi.org/md.v12i2.631

Tabel 5. Penilaian Kriteria ketersediaan air bersih dalam kawasan Ekowisata Mangrove Klawalu

\begin{tabular}{clccc}
\hline No. & \multicolumn{1}{c}{ Kiteria dan Unsur Penilaian } & Bobot & Nilai & $\begin{array}{c}\text { Skor } \\
\text { Total }\end{array}$ \\
\hline 1. & Volume air & 6 & 30 & 180 \\
2. & Jarak lokasi air bersih terhadap lokasi obyek & 6 & 30 & 180 \\
3 & Dapat tidaknya / kemudahan air dialirkan ke objek & 6 & 25 & 150 \\
4. & Kelayakan dikonsumsi & 6 & 20 & 120 \\
5. & Ketersediaan & 6 & 30 & 180 \\
\hline & Jumlah Skor Total & & $\mathbf{1 3 5}$ & $\mathbf{6 7 5}$ \\
\hline
\end{tabular}

Sumber: Data Primer 2019

Hasil penilaian terhadap pengembangan kawasan mangrove Klawalu menunjukkan bahwa kawasan ini layak untuk dikembangkan. Besarnya nilai potensi daya tarik yang dimiliki kawasan serta kemudahan akses menuju kawasan serta dilengkapi dengan sarana dan prasarana penunjang yang sangat mendukung, bahkan ketersediaan air bersih yang menunjang membuat kawasan ini menjadi sangat nyaman dan strategis untuk dikembangkan.

Tingkat keberhasilan pengelolaan kawasan mangrove Klawalu sangat didukung oleh karakteristik spesifik lingkungan mangrove yang masih terjaga. Hal ini merupakan keunikan wilayah yang perlu dipertahankan. Purwanto dkk (2014) menyatakan bahwa terjaganya keanekaragaman hayati dan kelestarian ekosistim merupakan modal yang sangat berarti bagi pengembangan ekowisata. Ekowisata diharapkan tidak hanya dapat mendorong pertumbuhan ekonomi secara regional maupun lokal untuk peningkatan kesejahteraan masyarakat, namun juga kelestarian sumber daya alam dan keanekaragaman hayati sebagai obyek dan daya tarik wisata.

\section{KESIMPULAN}

Potensi ekowisata objek wisata hutan mangrove Klawalu Kota Sorong didominasi oleh ekosistem tanaman mangrove. Hasil penilaian terhadap kawasan menunjukkan bahwa nilai obyek dan daya tarik kawasan cukup tinggi dengan dukungan aksesibilitas, sarana dan prasarana serta ketersedian air bersih. Bila kawasan ini dikelola dengan baik maka kondisi ekosistem mangrove akan tetap terjaga dan pendapatan sampingan masyarakat melalui ekowisata juga dapat meningkat.

\section{DAFTAR PUSTAKA}

[PHKA]. Pedoman Analisis Daerah Operasi Obyek dan Daya Tarik Wisata Alam. 2003. Bogor: Direktorat Jendral Perlindungan Hutan dan Konservasi Alam

Alaeddinoglu F, Turker N, Can AS, Ozturk S. 2013. Basic Characteristics, Motivation, and Activities of Ecotourists: A Case of Lake Van Basin Area, Turkey. Jurnal of Science. 6(3): 91-107 
Ginting IA, Panata P, Rahmawati. 2013. Penilaian dan Pengembangan Potensi Objek dan Daya Tarik Wisata Alam di Taman Wisata Alam (TWA) Sibolangit. Jurnal Universitas Sumatera Utara Medan.

Jarisetouw, Y.M.G. 2005. Analisa degradasi hutan mangrove pada kawasan wisata Teluk Youtefa Kota Jayapura. [Skripsi] Universitas Negeri Papua. Manokwari.

Mundoni D, Siburian R H. 2019. Profil ertumbuhan Baringtonia asiatica pada teluk Wosidori Kabupaten Manokwari. Jurnal Median Vol 11. No.3 (2019). DOI: https://doi.org/10.33506/md.v11i3.631

Purwanto S, Syaufina L, Gunawan A. 2014. Kajian potensi dan daya dukung Taman Wisata Alam Bukit Kelam untuk strategi pengembangan ekowisata. J Pengelolaan Sumberdaya dan Lingkungan 4(2):119-125. 